\title{
Health education on diabetes at a South African national science festival
}

\author{
M Mhlongo, ${ }^{1}$ BPharm; P Marara, ${ }^{1}$ BPharm; K Bradshaw, ${ }^{2} \mathrm{PhD}$; S C Srinivas, ${ }^{1} \mathrm{PhD}$, PGDHE
}

${ }^{1}$ Faculty of Pharmacy, Rhodes University, Grahamstown, South Africa

${ }^{2}$ Department of Computer Science, Rhodes University, Grahamstown, South Africa

Corresponding author: S C Srinivas (s.srinivas@ru.ac.za)

\begin{abstract}
Background. Diabetes is one of the non-communicable diseases with a major negative impact on the health and development of South Africans. Empowering the population's understanding of the condition, with health-literacy appropriate approaches, is one of the interventions that allows discussions around the prevention of diabetes.

Objective. To determine the effects of a health education programme on increasing knowledge about diabetes and encouraging preventive measures. Method. A public health education exhibition was held by a pharmacy student at a national science festival. It incorporated presentations, posters, health models, word-search games, information leaflets and a computer-based quiz consisting of pre- and post-intervention questions.

Results. Junior and senior school learners participated in the computer-based quiz. Results from the junior school pre-intervention phase showed that learners had a fair prior knowledge of diabetes, with an overall score of $52.8 \%$. Improvement in their overall mean score at the $5 \%$ significance level was noted $(p=0.020$ ). There was a significant difference in the mean score after the intervention at the $1 \%$ level (government schools: 65.5 (standard error (SE) 3.1)\%, independent schools: $45.9(6.2) \%$; $p=0.006)$. Of the senior learners $53.7 \%(n=137)$ indicated that they use computers at school, while 118 $(46.3 \%)$ did not have access to computers. The improvement in overall knowledge of the senior participants after the intervention was significant at the $0.1 \%$ level $(p<0.001)$.

Conclusion. The health education offered by the pharmacy student's project was interactive and used an interdisciplinary approach to improve health literacy and raise awareness of diabetes. This is a tested intervention that may be adopted for improving health literacy among schoolchildren.
\end{abstract}

Afr J Health Professions Educ 2018;10(1):26-30. DOI:10.7196/AJHPE.2018.v1011.887

Non-communicable diseases (NCDs) are the leading cause of death worldwide. Although NCDs are on the rise in both developed and developing countries, they affect low- and middle-income countries (LMICs) inordinately. ${ }^{[1]}$ Evidence shows that NCDs continue to rise owing to the prevalence of unhealthy diets, excessive alcohol consumption, smoking and lack of physical activity. ${ }^{[2,3]}$ Such behavioural and lifestyle risk factors can be addressed by increasing primary prevention, public awareness and understanding of NCDs. ${ }^{[4]}$ Health education initiatives and improved health literacy have been shown to be important to improve primary prevention and reduce NCD-related disparities in LMICs. ${ }^{[5]}$

According to the World Health Organization (WHO), diabetes contributes $6 \%$ to the mortality rate in South Africa (SA). ${ }^{[6]}$ The International Diabetes Federation (IDF) projects that these statistics will double by $2040 .{ }^{[7]}$ According to the IDF, SA reported 2.28 million cases of diabetes in 2015. ${ }^{[7]}$ This has a negative effect on the health status of SA citizens, given that SA has moved to a quadruple burden of disease according to the Statistics South Africa report. ${ }^{[8]}$ Diabetes is a significant contributor to this burden ${ }^{[9,10]}$ and, with other NCDs, has serious financial implications, particularly on the national government and people of productive age (15 - 64 years). ${ }^{[10,11]}$ Sustainable Development Goal 3 and health education are important tools to achieve sustainable health development in LMICs. ${ }^{[12]}$

The role of healthcare professionals in empowering the public with regard to health matters is vital. ${ }^{[13,14]}$ Pharmacists play an important role in public health, and hands-on health promotion training is therefore essential for pharmacy students. ${ }^{[10]}$ The focal point of competency-based training is to improve pharmacists' knowledge and communication skills with regard to NCDs such as diabetes, so that tailor-made and culturally appropriate information is conveyed to patients and the general public. ${ }^{[10]}$ Healthcare empowerment is key to the prevention of diabetes ${ }^{[15,16]}$ and should be implemented by an interdisciplinary team. It provides an effective means of conducting public health education, as it allows the use of technology-based interventions to positively influence health behaviour outcomes. ${ }^{[17]}$ Healthcare empowerment can be achieved by health education, and it is a vital rudimentary intervention strategy in which learning goals and community service are combined in ways that allow both the student and community to benefit. ${ }^{[18,19]}$ Health education outside the classroom facilitates meaningful learning by enabling pharmacy students to transpose ${ }^{[20]}$ course content into real-life scenarios, which may be difficult to achieve in any other way for the analysis and understanding of their experience with the community. ${ }^{[21]}$

This article reports on the effect of a pharmacy student-developed public health education exhibit at a national science festival (NSF) on the understanding of diabetes, its causes and prevention, among a group of school learner attendees.

\section{Method \\ Research design}

A descriptive cross-sectional study was conducted. Quantitative data were collected pre- and post-intervention via a computer-based quiz. 


\section{Research procedure \\ Pilot study}

The pharmacy student first conducted a pilot test using a quiz for senior learners (grade 8 - 12) and one for junior learners (grade 1 - 7). Learners from a mathematics and science club for disadvantaged local schools in the Eastern Cape assisted during this phase. Names of the participants were not collected to preserve anonymity and confidentiality. Participants provided feedback for acceptability of the quiz on diabetes. A presentation on diabetes was delivered in isiXhosa and English. It used posters, games and health models to clarify its content. Changes to the quiz were implemented based on feedback obtained during the pilot study.

\section{Data collection}

An interdisciplinary collaboration with the Department of Computer Science at Rhodes University, Grahamstown, resulted in the design of the computerbased quiz software using Microsoft PowerPoint (Microsoft, USA), and known as the BKnow program, to collect pre- and post-intervention data, while participants attempted to answer the computer-based quiz. School learners needed to use only three buttons on the computer keyboard while answering the quiz. Pharmacy students manning the exhibit instructed participants on how to operate the computer, as most of the schoolchildren who attended the NSF were from rural and township schools, and had little or no prior experience of using a computer. ${ }^{[22]}$ Senior and junior students had separate quizzes. The pre-intervention questionnaire was followed by the intervention slide show on the computer. Immediately thereafter, the post-intervention questionnaire was made available.

\section{Intervention}

In addition to the interactive computer-based quiz, participants received an interactive presentation on diabetes, which included a model to demonstrate the benefits of a healthy diet and the consequences of an unhealthy one; a poster; an anatomical model of the alimentary system; a word search game; and a practical demonstration of the measuring tools for body mass index (BMI) and blood pressure. The anatomy board of the alimentary tract was used to show the organs affected by diabetes, and the interactive model on making healthy dietary lifestyle choices showed which choices predispose patients to diabetes. The poster was used to visualise and summarise information, and was presented to enhance the learning experience. Bilingual take-home leaflets (available in isiXhosa and English) were given to participants who attended the pharmacy health exhibition after the presentation. Thus they could take home basic information on diabetes to share with their families or community members. Schoolchildren received a word-search game, allowing interactive learning. The game reinforced key concepts associated with diabetes. The interactive presentation created a learning atmosphere for participants, which included schoolchildren, their parents and their teachers. The option to measure blood pressure and BMI was only available after receiving informed consent from volunteering participants.

\section{Data analysis}

To assess whether the intervention made a difference in the understanding of diabetes, its causes and treatment, dependent $t$-tests on percentage scores for the junior and senior quizzes and McNemar $\chi^{2}$ tests on the percentage of correct answers obtained for each question before and after the intervention were conducted. Individual $t$-tests and analysis of variance
(ANOVA) procedures were performed to test the effects of age, gender and type of school (independent or government-funded) on quiz percentage scores before and after the intervention. Mean and standard error (SE) were calculated for pre- and post-intervention scores. All tests were performed using the statistical programming language $\mathrm{R}$, with significance set at the $5 \%$ level. Separate analyses were performed on the junior and senior learners' quiz results.

\section{Ethical approval}

The project was approved by the Rhodes University Pharmacy Ethics Committee (ref. no. PHARM 2016-6).

\section{Results \\ Junior learners}

Demographics of the participants (age, grade, school and province of residence) were captured by the first 5 questions of the quiz, in which 113 learners took part. Data obtained show that 51 participants (45.1\%) were $\leq 7$ years of age, 23 (20.4\%) were between 8 and 10 years, 27 (23.9\%) between 11 and 13 years, and $12(10.6 \%)$ were $\geq 14$ years. Of the total, $65(57.5 \%)$ were female and 48 (42.5\%) male. Regional distribution showed that 102 (90.3\%) were from the Eastern Cape, and the remainder were based in the other SA provinces. Demographics further showed that 88 (77.9\%) participants attended government schools, while the remaining $25(22.1 \%)$ attended private or independent schools. The numbers of learners who made use of or did not use computers at school were almost equal: 56 (49.6\%) and 57 (50.4\%), respectively.

\section{Pre-intervention results}

Results from the pre-intervention questions, presented in Table 1, showed that learners had fair prior knowledge of diabetes, its effects, and how the disease can be prevented (overall mean score 52.8\%). Questions 4 and 5 had the lowest correct percentage scores: 'Why is insulin produced by the body?' and 'A person can prevent getting diabetes by eating what?' - for which $40.7 \%$ and $35.4 \%$ of the participants, respectively, provided correct answers. Conversely, Questions 2 and 7 had the highest correct scores: 'Can uncontrolled diabetes cause death?' and 'If diabetes is uncontrolled, it leads to what?' - for which $71.7 \%$ and $62.0 \%$ of the participants, respectively, answered correctly (Table 1).

\section{Comparison of pre- and post-intervention results}

Of the 113 learners who answered the pre-intervention questions, 72 (64\%) advanced to the post-intervention questions. To analyse the change in learners' knowledge after the intervention, one-sided McNemar dependent $\chi^{2}$ tests were used. These results are presented in Table 1.

The intervention resulted in a significant increase $(p<0.05)$ in correct responses to Question 3, relating to what life would be like for children with diabetes $(p=0.012)$. No significant improvement was observed in the number of correct answers given to any of the other questions. However, an improvement in the participants' overall percentage score at the 5\% significance level was noted $(p=0.020)$.

Results showed no significant gender differences for either the pre- or post-intervention mean (SE) percentage scores (pre-intervention, male: 54.0 (3.8)\%, female: 53.6 (3.4)\%; $p=0.930$; post-intervention, male: $61.1(3.9) \%$, female: $62.5(4.4) \% ; p=0.809)$. No significant difference in mean percentage score between participants from government and independent schools was 
noted before the intervention (pre-intervention, government: $55.2(2.8) \%$, independent: 48.0 (5.7)\%; $p=0.257$ ). However, after the intervention there was a significant difference at the $1 \%$ level (post-intervention, government: 65.5 (3.1)\%, independent: 45.9 (6.2)\%; $p=0.006)$. No significant difference $(p>0.05)$ was observed between the age groups for the pre-intervention mean percentage scores. However, a significant difference at the $5 \%$ level was noted for post-intervention scores $(p<0.05)$ (Table 2).

Significant differences were also noted between pre- and post-intervention scores for the following groups: (at the $0.1 \%$ significance level) for learners from government schools $(p<0.001)$; (at the $0.1 \%$ significance level) for participants in the 11 - 13 age category ( $p=0.009$ ); and (at the 5\% significance level) for male participants $(p=0.018)$ and participants in the $\leq 7$-year age category $(p=0.027)$.

\section{Senior learners}

As in the junior school quiz, the demographics of the 255 participants in the senior quiz were captured by Questions $1-5$. Data show that 62 participants $(24.3 \%)$ were $\leq 12$ years old, $84(32.95 \%)$ were 13 - 15 years, $84(32.95 \%)$ were between 16 and 19 years, and $25(9.8 \%)$ were $\geq 20$ years. Of the total, 141 (55.3\%) were female and 114 (44.7\%) were male. Regional distribution indicated that $235(92.2 \%)$ attended or had attended a school in the Eastern Cape, while the remaining $20(7.8 \%)$ were schooled elsewhere in SA

\section{Table 1. Junior school quiz results}

\begin{tabular}{|c|c|c|c|c|}
\hline Question & $\begin{array}{l}\text { Correct answers }(N=113), \\
n(\%)\end{array}$ & $\begin{array}{l}\text { Correct responses for } \\
\text { pre-intervention scores } \\
(N=72), \text { mean }(\%)\end{array}$ & $\begin{array}{l}\text { Correct responses for } \\
\text { post-intervention scores } \\
(N=72), \text { mean }(\%)\end{array}$ & $\begin{array}{l}p \text {-value } \\
\text { (one-sided) }\end{array}$ \\
\hline 1. Diabetes is when your body has? & $66(58.4)$ & $40(55.6)$ & $43(59.7)$ & 0.677 \\
\hline 2. Can uncontrolled diabetes cause death? & $81(71.7)$ & $51(70.8)$ & $51(70.8)$ & 1 \\
\hline 3. Which of these statements is correct? & $60(53.1)$ & $41(57.0)$ & $54(75.0)$ & $0.012^{*}$ \\
\hline 4. Why is insulin produced by the body? & $46(40.7)$ & $27(37.5)$ & $30(41.7)$ & 0.719 \\
\hline 5. A person can prevent getting diabetes by eating what? & $40(35.4)$ & $29(40.3)$ & $33(45.8)$ & 0.387 \\
\hline 6. Which of the following statements is incorrect? & $55(48.7)$ & $39(54.2)$ & $47(65.3)$ & 0.186 \\
\hline 7. If diabetes is uncontrolled, it leads to: & $70(62.0)$ & $44(61.1)$ & $53(73.6)$ & 0.066 \\
\hline Overall mean (\%) & - & $53.8(5.0)$ & $61.7(5.8)$ & $0.020^{*}$ \\
\hline${ }^{*} p<0.05$. & & & & \\
\hline
\end{tabular}

Table 2. Pre- and post-intervention scores for different age groups (junior quiz)

\begin{tabular}{lll}
\hline Age group, years & $\begin{array}{l}\text { Pre-intervention score, } \\
\text { mean (\%) }\end{array}$ & $\begin{array}{l}\text { Post-intervention score, } \\
\text { mean }(\%)\end{array}$ \\
\hline$\leq 7$ & $51.1(6.1)$ & $59.0(7.1)$ \\
$8-10$ & $63.4(7.1)$ & $66.1(8.3)$ \\
$11-13$ & $51.1(4.8)$ & $67.0(5.6)$ \\
$\geq 14$ & $50.0(9.8)$ & $47.6(11.4)$ \\
Analysis of variance, pre-intervention: $F=1.439 ; d f=3,68 ; p=0.239 ;$ post-intervention: $F=1.255 ;$ \\
$d f=3,68 ; p=0.297$.
\end{tabular}

Demographics also showed that $232(91.0 \%)$ and 23 (9.0\%) participants attended government and independent schools, respectively.

Some learners $(n=137 ; 53.7 \%)$ responded that they had used computers at school before, while 118 (46.3\%) had not.

\section{Pre-intervention results}

Results from the pre-intervention questions are shown in Table 3.

Based on the results of the pre-intervention study, learners had fair prior knowledge of diabetes, its effects, and how it could be prevented (overall score 59.1\%). Questions 9, 4 and 7 had the lowest correct scores. These were:

Table 3. Senior school quiz results

\begin{tabular}{|c|c|c|c|c|}
\hline Question & $\begin{array}{l}\text { Correct answers } \\
(N=255), \\
n(\%)\end{array}$ & $\begin{array}{l}\text { Correct responses } \\
\text { for pre-intervention } \\
\text { scores }(N=139) \text {, } \\
\text { mean }(\%)\end{array}$ & $\begin{array}{l}\text { Correct responses } \\
\text { for post-intervention } \\
\text { scores }(N=139), \\
\text { mean }(\%)\end{array}$ & $\begin{array}{l}p \text {-value } \\
\text { (one-sided) }\end{array}$ \\
\hline 1. What is diabetes? & $189(74.1)$ & $114(82.0)$ & $113(81.3)$ & 1 \\
\hline 2. How does someone get diabetes? & $200(78.4)$ & $113(81.3)$ & $115(82.7)$ & 0.860 \\
\hline 3. How does someone get to know if they have diabetes? & $183(71.7)$ & $101(72.7)$ & $113(81.3)$ & 0.074 \\
\hline 4. What is insulin? & $88(34.5)$ & $48(34.5)$ & $58(41.7)$ & 0.175 \\
\hline 5. Uncontrolled diabetes is a disease that may cause damage to what? & $134(52.6)$ & $78(56.1)$ & $93(66.9)$ & $0.041^{*}$ \\
\hline 6. The onset of diabetes can be delayed or prevented by? & $172(67.5)$ & $99(71.2)$ & $108(77.7)$ & 0.151 \\
\hline 7. Which of the following is least likely to cause diabetes? & $117(45.9)$ & $66(47.5)$ & $87(62.6)$ & $0.001^{* *}$ \\
\hline 8. Why do we need to avoid obesity? & $135(52.9)$ & $83(59.7)$ & $90(64.8)$ & 0.391 \\
\hline 9. True or false: Uncontrolled diabetes can cause high blood pressure & $86(33.7)$ & $44(31.7)$ & $75(54.0)$ & $<0.001^{* * *}$ \\
\hline 10. Which of the following statements is incorrect? & $179(70.2)$ & $98(70.5)$ & $104(74.8)$ & 0.440 \\
\hline 11. Which of the following statements is correct? & $174(68.2)$ & $99(71.2)$ & $113(81.3)$ & $0.014^{*}$ \\
\hline Overall mean (\%) & - & $61.7(3.5)$ & $69.9(3.8)$ & $<0.001^{\star * *}$ \\
\hline
\end{tabular}


'True or false: Uncontrolled diabetes causes high blood pressure', 'What is insulin?' and 'Which of the following is least likely to cause diabetes?'. Results showed that only $33.7 \%, 34.5 \%$ and $45.9 \%$ of the participants answered the respective questions correctly. Questions 2 and 1, 'How does someone get diabetes?' and 'What is diabetes?', had the highest correct scores with $78.4 \%$ and $74.1 \%$ correct answers, respectively (Table 3 ).

\section{Comparison of pre- and post-intervention results}

Of the 255 senior school participants who answered the pre-intervention questions, 139 (55\%) continued to the post-intervention ones. McNemar's dependent one-sided $\chi^{2}$ test was used to analyse each question; the results are shown in Table 3.

The intervention resulted in a significant increase in correct responses to four of the questions. Question 9 showed improvement at the $0.1 \%$ significance level $(p<0.001)$, while Question 7 showed improvement at the $1 \%$ significance level $(p=0.001)$. Furthermore, Questions 5 and 11 showed improvement at the $5 \%$ significance level ( $p=0.041$ and 0.014 , respectively). Improvement in the overall knowledge of participants after the intervention was significant at the $0.1 \%$ significance level $(p<0.001)$.

Results indicated no significant gender differences for either the preor post-intervention mean percentage scores (pre-intervention, male: 60.7 (2.5)\%, female: 62.7 (2.5)\%; $p=0.582$; post-intervention, male: 68.3 (2.7)\%, female: $71.6(2.8) \%$; $p=0.389)$. No significant differences in mean percentage scores were found between participants from government and independent schools (pre-intervention, government: $62.5(1.8) \%$, independent: 53.1 (5.70)\%; $p=0.121$; post-intervention, government: 71.3 (2.0)\%, independent: $56.6(6.2) \%$; $p=0.123$ ). There were no significant agerelated differences in either the pre- or post-intervention mean percentage scores. The mean (SE)\% scores of the participants in the age groups are shown in Table 4.

Overall, significant differences were noted between pre- and postintervention mean percentage scores for the following groups: for participants in the 16 - 19-year age group, male participants, and learners from government schools (at the $0.1 \%$ significance level) $(p<0.001$ for each); and for female participants (at the $1 \%$ significance level) $(p=0.002)$ and participants in the 13 - 15-year age group (at the $1 \%$ significance level) $(p=0.002)$. It is interesting to note that no change took place in the mean percentage scores of the $\geq 20$-year age group.

\section{Discussion}

The computer-based quiz was used for health education and as a mechanism for raising awareness and encouraging healthier lifestyle decisions, particularly among the young attendees at the NSF. This project targeted schoolchildren, as the health education they received could assist them in

Table 4. Pre- and post-intervention scores for different age groups (senior quiz)

\begin{tabular}{lll}
\hline Age groups, years & $\begin{array}{l}\text { Pre-intervention } \\
\text { score, mean (\%) }\end{array}$ & $\begin{array}{l}\text { Post-intervention score, } \\
\text { mean (\%) }\end{array}$ \\
\hline$\leq 12$ & $61.4(4.3)$ & $68.9(4.6)$ \\
$13-15$ & $61.7(5.3)$ & $70.4(5.7)$ \\
$16-19$ & $62.5(5.1)$ & $72.4(5.6)$ \\
$\geq 20$ & $58.3(7.4)$ & $58.3(8.0)$
\end{tabular}

Analysis of variance, pre-intervention: $F=0.129 ; d f=3,135 ; p=0.943$; post-intervention: $F=1.287$ $d f=3,135 ; p=0.282$. understanding aspects related to the prevention of diabetes. This approach is important, as it keeps a healthy population healthy.

Evidence shows that more children are becoming obese and are thus increasingly prone to developing NCDs. ${ }^{[5]}$ Therefore, the results are encouraging, as the majority (45.1\%) of the junior school quiz participants were $\leq 7$ years old. Child health education is important to address health literacy, especially in rural communities, where access to information is limited. Interestingly, demographic results obtained indicate that $90 \%$ of the junior and $92 \%$ of the senior school participants were from the Eastern Cape, the second poorest province in SA. ${ }^{[23]}$

Diabetes is one of the major diseases contributing to the rise of NCDs, and the resulting mortality in the productive age group has a negative economic impact on individuals, families and governments in LMICs. ${ }^{[1,24]}$ This further decreases the gross domestic product (GDP) of LMICs, where $>75 \%$ of NCD-related mortality occurs. ${ }^{[25]}$ The quadruple burden of diseases in $\mathrm{SA}^{[8,26]}$ means that the poorest provinces, such as the Eastern Cape ${ }^{[23]}$ will be inordinately affected as the global burden of disease rises. By working towards the global goal of reducing NCD mortality rates by $2 \%$ yearly, significant improvements to the GDP and health coverage can be achieved, ${ }^{[25]}$ along with a cost-effective health education tool.

Both junior and senior school participants had fair prior knowledge of diabetes, according to pre-intervention quiz results. Only $64 \%$ of the junior and $55 \%$ of the senior school quiz participants in the pre-intervention questions advanced to the post-intervention ones. As most participants attended rural government schools, where the English language acts as a barrier to effective learning, lack of understanding of the questions might have been a factor that led to the participants not continuing to the postintervention questions. Moreover, as a significant improvement on the postintervention results was only observable for Question 3 for the junior school quiz, with no significant improvement with regard to other questions, it shows the need for more community engagement from pharmacy students as an intervention to promote health education and learning. Senior school participants' overall knowledge on diabetes improved in the postintervention section.

Demographics show that there were more female participants in both the senior and junior phase quizzes. A focus on female participants is important, as $42 \%$ of women in SA are obese. ${ }^{[27,28]}$ Food companies, manufacturers and multinationals are profit centred, which has a detrimental effect on the population, because these stakeholders seek to influence WHO guidelines on sugar restrictions in favour of maximised profits. ${ }^{[29]}$ World Health Day 2016 focused on diabetes mellitus; this health education was aligned to it. ${ }^{[30]}$

Opportunities to design a poster, a bilingual information leaflet, a word-search game and a health model to explain healthy lifestyle choices, in addition to the interactive computer-based quiz, could have made this project unique for pharmacy students in developing a deeper understanding of the benefits of hands-on interactive health education. Use of multiple materials to focus on preventing and reducing NCDs offered an exciting and creative way of broadening the horizon of young participants.

\section{Conclusion}

The public health education exhibit on diabetes demonstrated the role of a cost-effective approach to reach out to the attendees and the broader community during an NSF. It accommodated learners from public and private schools, and illustrated ways in which health education aimed at children could lead to dissemination of health information for improved health literacy and disease prevention. 
Acknowledgements. The authors wish to thank the facilitators and students of the Khanya Maths and Science Club for their participation in pilot testing the quizzes. Mr N Borland is kindly acknowledged for his technical and logistics assistance. Drs R Tandlich and S Khamanga are acknowledged for their support.

Author contributions. This health promotion project was carried out as a part of Mr M Mhlongo's final-year BPharm research project. He manned the health promotion exhibit during the Scifest and was assisted adequately to write the first draft of the manuscript. Ms P Marara, a Master's student working with Prof. S C Srinivas, was a mentor to Mr Mhlongo during the Scifest project and also assisted with manning the exhibit when Mr Mhlongo had to attend his practical or other academic commitments at the University. Ms Marara was also a mentor during the manuscript-writing phase. Dr K Bradshaw provided technical support related to the capture of the data during the Scifest and in analysing the data. Dr Bradshaw wrote the results section of the manuscrip. She edited the final version of the manuscript before submission and also when the reviewers' feedback was received. Prof. Srinivas conceptualised and supervised the Scifest health promotion project. She also co-ordinated all the logistics required at various stages of the Scifest, such as pilot testing, setting up the exhibit and schedules of manning the exhibit, and edited the various drafts of the manuscript until completion.

Funding. The Faculty of Pharmacy, Rhodes University, is gratefully acknowledged for the funding of this project. Funds from Rhodes University's Inaugural Distinguished Vice-Chancellor's Community Engagement Award made to Prof. Srinivas and Ms W Wrench are acknowledged. These funds supported the language-editing costs of this manuscript.

Conflicts of interest. None.

1. World Health Organization. 2008 - 2013 Action Plan for the Global Strategy for the Prevention and Control of Noncommunicable Diseases. Geneva: WHO, 2008

2. Raal FJ. The cardioprotective diet - carbohydrates versus fat. S Afr J Diabetes Vasc Dis 2015;12(1):4

3. Stuckler D, McKee M, Ebrahim S, Basu S. Manufacturing epidemics: The role of global producers in increased consumption of unhealthy commodities including processed foods, alcohol, and tobacco. PLOS Med 2012;9(6):e1001235. https://doi.org/10.1371/journal.pmed.1001235

4. Ahmed MSAM. Lifestyle measures for primary prevention of T2 diabetes mellitus (T2DM). Ind J Comm Healt 2014;26(4):450.

5. Taggart J, Williams A, Dennis S, et al. A systematic review of interventions in primary care to improve health literacy for chronic disease behavioral risk factors. BMC Fam Pract 2012;13:49. https://doi.org/10.1186/14712296-13-49

6. World Health Organization. Noncomunicable Diseases: Country Profiles 2014. Geneva: WHO, 2014. http:// www.who.int/nmh/countries/zaf_en.pdf?ua=1 (accessed 20 March 2016).
7. International Diabetes Federation. IDF Africa members. 2015. http://www.idf.org/membership/afr/south-africa (accessed 20 March 2016)

8. Bradshaw D, Groenewald P, Laubscher R, et al. MRC Policy Brief: Initial Estimates from the South Africa National Burden of Disease Study, 2000. Cape Town: MRC, 2003. http://www.mrc.ac.za/policybriefs initialestimates.pdf (accessed 20 March 2016).

9. Mayosi BM, Flisher AJ, Lalloo UG, Sitas F, Tollman SM, Bradshaw D. The burden of non-communicable diseases in South Africa. Lancet 2009;374(9693):934-947. https://doi.org/10.1016/S0140-6736(09)61087-4

10. Tasic L, Pesic V. Identification of risk factors for diabetes type 2 and components of pharmacists' interventions in community pharmacy setting: A Serbian pilot study. Indian J Pharm Educ Res 2016;50(1):90-102. https://dol org/10.5530/ijper.50.1.12

11. World Bank. World Bank open data: Population ages 15 - 64 (\% of total). 2017. http://data.worldbank.org/ indicator/SP.POP.1564.TO.ZS (accessed 18 March 2016).

12. United Nations Development Program. Sustainable development goals. 2016. http $/ /$ www undp.org/content undp/en/home/sdgoverview/post-2015-development-agenda.html (accessed 2 May 2016).

13. Blom L, Krass I. Introduction: The role of pharmacy in patient education and counselling. Patient Educ Couns 2011;83(3):285-287. https://doi.org/10.1016/j.pec.2011.05.021

14. Irlam J, Pienaar L, Reid S. On being agents of change: A qualitative study of elective experiences of medical students at the Faculty of Sciences, University of Cape Town, South Africa. Afr J Health Professions Educ 2016;8(1):41-44. https://doi.org/10.7196\%2FAJHPE.2016.v8i1.540

15. Mitchell B, Armour C, Lee M, et al. Diabetes medication assistance service: The pharmacist's role in supportin patient self-management of type 2 diabetes (T2DM) in Australia. Patient Educ Couns 2011;83(3):288-294. https://doi.org/10.1016/j.pec.2011.04.027

16. Healthcare Information for All. About HIFA. 2015. http://www.hifa2015.org/about/hifa2015-in-context/ (accessed 21 March 2016)

17. Sawesi S, Rashrash M, Phalakornkule K, Carpenter JS, Jones JF. The impact of information technology on patient engagement and health behavior change: A systematic review of the literature. JMIR Med Inform 2016;4(1):el https://doi.org/10.2196/medinform.4514

18. Bandy J. What is service learning or community engagement. 2016. https://cft.vanderbilt.edu/guides-sub-pages teaching-through-community-engagement/ (accessed 20 March 2016).

19. Kruger SB, Nel MM, van Zyl GJ. Implementing and managing community-based education and service Kruger SB, Nel MM, van Zyl GJ. Implementing and managing community-based education and service
learning in undergraduate health sciences programmes: Students' perspectives. Afr J Health Professions Educ learning in undergraduate health sciences programmes: Students' perspectives. Afr J Health Professions Educ 2015;7(2):161-164. https://doi.org/10.7196\%2FAJHPE.333

20. Hamner J, Wilder B, Byrd L. Lessons learned: Integrating a service learning community-based partnership into the curriculum. Nurs Outlook 2007;55(2):106-110. https://doi.org/10.1016/j.outlook.2007.01.008

1. Mouton J, Wildschut L. Service learning in South Africa: Lessons learnt through systematic evaluation. Acta Acad Suppl 2005(3):116-150.

22. Srinivas SC, Wrench WM, Bradshaw K, Dukhi N. Diabetes mellitus: Preliminary health-promotion activity based on service-learning principles at a South African national science festival. J Endocrinol Metab Diabetes S Af 2011:16(2):101-106

23. Lehohla P. Poverty Profile of South Africa: Application of the Poverty Lines in the LCS 2008/2009. Pretoria: Statistics South Africa, 2012.

24. Horton R. Chronic diseases: The cause for urgent global action. Lancet 2007;370(9603):1881-1882. https://doi. org/10.1016/S0140-6736(07)61701-2

25. Abegunde D, Mathers CD, Adam T, Ortegon M, Strong K. The burden and cost of chronic diseases in low-income and middle-income countries. Lancet 2007:370(9603):1929-1938. htrps//doiorg/10.1016/S0140-6736(07)61696-1

26. Perez AM, Ayo-Yusuf O A, Hofman K, et al. Establishing a health promotion and development foundation in South Africa. S Afr Med J 2013;103(3):147-149. https://doi.org/10.7196\%2FSAMJ.628

27. South African Medical Research Council. South African women show high levels of obesity and overweight. 2014. http://www.mrc.ac.za/Media/2014/14press2014.htm (accessed 29 May 2014).

28. Ng M, Fleming T, Robinson M, et al. Global, regional, and national prevalence of overweight and obesity in children and adults during 1980 - 2013: A systematic analysis for the Global Burden of Disease Study 2013. Lancet 2014;384(9945):766-781. https://doi.org/10.1016/S0140-6736(14)60460-8

29. Stuckler D, Reeves A, Loopstra R, McKee M. Textual analysis of sugar industry influence on the WHO's sugar intake guideline. Bull World Health Organ 2016;94(8):566-573. https://doi.org/10.2471/BLT.15.165852

30. World Health Organization. World Health Day 2016: Beat diabetes. 2016. http://www.who.int/campaigns/worldhealth-day/2016/en/ (accessed 9 March 2018).

Accepted 14 September 2017 